\title{
Interaction of Physical Exposures and Occupational Factors on Sickness Absence in Automotive Industry Workers
}

\author{
Fateme Valirad ${ }^{1}$, Mostafa Ghaffari ${ }^{1,2}$, Alireza Abdi ${ }^{2}$, Mirsaeed Attarchi ${ }^{1}$, \\ Seyed Farzin Mircheraghi ${ }^{3} \&$ Saber Mohammadi $^{1}$ \\ ${ }^{1}$ Occupational Medicine Department, Faculty of Medicine- Iran University of Medical Sciences, Tehran, Iran \\ ${ }^{2}$ Brain and Spinal Injury Research Center (BASIR), Imam Khomeini Hospital, Tehran University of Medical \\ Sciences, Tehran, Iran \\ ${ }^{3}$ Internal Medicine Departments, Faculty of Medicine, Gonabad University of Medical Sciences, Gonabad, Iran \\ Correspondence: Saber Mohammadi, Associate Professor of occupational Medicine, Faculty of Medicine, Iran \\ University of Medical Sciences, Rasoul Akram Hospital, Tehran-Iran. E-mail: sabermohammadi@gmail.com
}

Received: January 20, 2015 Accepted: February 25, 2015 Online Published: April 23, 2015

doi:10.5539/gjhs.v7n6p276 URL: http://dx.doi.org/10.5539/gjhs.v7n6p276

\begin{abstract}
Introduction: Increased sickness absence in recent years has been a trouble making issue in industrial society. Identify the causes of sickness absence and its influencing factors, is an important step to control and reduce its associated complications and costs. The aim of this study was to evaluate main factors associated with the incidence of sickness absence.

Procedure: In 2012, a cross-sectional study on 758 employees of a car accessories producing company was applied and relevant information about the number of days and episodes of sickness absence, Disease resulting in absence from work, personal features, occupational factors and physical exposures were collected. To determine risk factors associated with sickness absence, Logistic regression analysis was used.
\end{abstract}

Results: The most common diseases leading to sickness absence in order of frequency were Respiratory diseases, musculoskeletal disorders, gastrointestinal diseases and injuries at work. Musculoskeletal disorders increased the danger of long term absence by 4/33 times. Blue collar and shift works were the most important occupational factors associated with the incidence of sickness absence. The main physical factors that affect incidence of sickness absence were frequent bending-twisting and heavy lifting.

Conclusion: Identifying controllable factors of sickness absence and trying to prevent and modify them such as compliance of ergonomic principals to decrease physical can be effective in reducing sickness absence.

Keywords: sickness absence, physical exposure, risk factors, shift work, blue collar

\section{Introduction}

Due to negative impacts on labor productivity, cumbersome costs and interference with production quality (d'Errico et al., 2012; Kremer et al., 2010; Ferrie et al., 2009; Head et al., 2008; Kivimaki et al., 2007; Zenz, 1994), sickness absence from work has attracted more attention in recent years and has become an important issue in industrialized societies (Lund et al., 2009; Zenz, 1994). Sickness Absence is a major socio-economic problem and imposes high costs on societies (d'Errico et al., 2012; Kremer et al., 2010; Ferrie et al., 2009; Head et al., 2008; Kivimaki et al., 2007; Rahme et al., 2006; Zenz, 1994). For example, during 2013 in UK, 131 million working days lost due to sickness absence (salus, 2011) and in 2012, 227 billion dollars were disbursed in United States of America, only to reduce productivity losses due to sickness absence (forbes, 2012).

Sickness Absence is a complex situation and has a multi-factorial etiology (Ferreira et al., 2012; Virtanen et al., 2008). According to previous studies, factors such as individual characteristics and occupational factors, affect the incidence and severity of Sickness Absence (d'Errico et al., 2012; Kristensen et al., 2010; Lund et al., 2009; Niedhammer et al., 2008; Virtanen et al., 2008; Duijts et al., 2007; Dekkers-Sanchez et al., 2007; Ose, 2005; Labriola et al., 2006; Bultmann et al., 2005; Vingrd et al., 2005; Zenz, 1994). Obviously, many of these factors are controllable and preventable. That's why many studies have been carried out to identify factors associated with the sickness absence in different industries and occupations. In a study conducted by Alavinia et al (2009) 
authors found that obesity, smoking and manual materials handling were important risk factors for moderate and long durations of sickness absences.

Given the particular importance of identifying the causes of absence from work and factors affecting it, further studies in this area would be beneficial. The aim of our study was to identify the causes of absence from work and examines the impact of individual factors, occupational and physical exposures on the incidence of Sickness Absence in the automotive industry workers.

\section{Methods}

\subsection{Study Design and Population}

This Cross-sectional study has been carried out since November 2011 till October 2012 on the employees of a car accessories production company in Tehran, Iran. Workers who had at least one year of experience were recruited on a voluntary basis. Distribution, collection and monitoring of response to the questionnaires performed by a general practitioner working in the HSE Unit. Some parts of job information such as dates of employment, working location and shift work status were extracted from company`s staffing and recruiting unit. This study was approved by the ethics committee of Iran University of medical sciences.

\subsection{Sickness Absence}

The SA data were extracted in 2011 from computerized system of HSE unit. This data include number of days missed, number of episodes of absence and illness resulting in sickness absence. The absences duration were divided into two groups of short term ( $<3$ day) and long term ( $\geq 3$ day) (Virtanen et al., 2008). Diseases were classified according to International Classification of Diseases version ten (ICD10) (WHO, 2010).

\subsection{Questionnaire and Determinants}

A self-administered questionnaire was used to collect information regarding the following variables: 1Socio-demographic factors such as age, sex, marital status and education level. 2- Lifestyle including smoking (number of years and number of cigarettes per day), height and weight were used to calculate BMI and subjects based on BMI number are divided into three groups of normal: $\mathrm{BMI}<25$, overweight: $25 \leq \mathrm{BMI}<30$ and obese: BMI $\geq 30$ (Ferreira et al., 2012). 3- Physical exposure: in order to assess this variable, the MUSIC (musculoskeletal intervention center)-Norrtalje questionnaire (Alipour et al., 2007) which contains 12 questions was used. The first question was a Visual Analog Scale (VAS) that evaluated the hard work of the workers. other questions assessed the duration of sitting at work,working in front of a computer screen and working with vibrating tools, vibration exposure levels, , frequency of bending and twisting of the back, Heavy lifting and so on .The answers to these questions should be chosen on a 5-point likert scale. Answer as never, a quarter of times and total score less than or equal to 30 were considered as low physical exposure and Answers as half, three quarters, always and total score greater than 30 were considered as high physical exposure.

\subsection{Statistical Analysis}

Sickness absence was our dependent variable in this study and independent variables were individual, socio-demographic, occupational and physical exposures. No absences subjects were considered as the reference group. Chi- square test was applied to compare qualitative variables and Binary logistic regression analysis was employed to determine the variables associated with SA. In all tests, the significant level was considered as 0/05 with confidence interval at $95 \%$ and data statistical analysis was carried out with SPSS software version 13.

\section{Results}

In this study, 956 questionnaires distributed among employees and 790 questionnaires were returned. The response rate was $82.63 \% .31$ questionnaires were excluded due to incomplete data and one questionnaire due to absence related to pregnancy. Finally, 758 questionnaires were analyzed. The average age of the sample was $35.08( \pm 7.03 \mathrm{SD})$ years and the range was from 21 years to 63 years. $94.3 \%$ of subjects were male. $51.7 \%$ of cases had abnormal BMI (overweight and obesity). $72 \%$ of participants were shift workers and $74 \%$ were blue collars.

The analysis of sickness absence showed that the $49.86 \%(\mathrm{n}=378)$ of respondents had sickness absence and about $60.84 \%(n=230)$ of this group had one absence episode, $30.15 \%(n=114)$ had two absence episodes and $9 \%$ $(\mathrm{n}=34)$ had three absence episodes. Mean duration of short term sickness absences was 1.69 days (Standard Deviation: 0.73) and Mean duration of long term sickness absences was 10.92 days (Standard Deviation: 13.7). The most common diseases leading to absence from work in order of frequency were upper respiratory diseases (77.08\%), musculoskeletal disorders $(8.88 \%)$, gastrointestinal disease $(5.15 \%)$ and injuries $(4.3 \%)$. The remaining other diseases percentages were low. Respiratory diseases and gastrointestinal disorders resulting in 
short term sickness absences while the musculoskeletal disorders and injuries leading to long term sickness absence periods. In this study, the results showed that the musculoskeletal diseases increased the risk of long term sickness absence 4.33 times $[(95 \% \mathrm{CI}=2.44-7.68), \mathrm{p}<0.001]$ and this risk for injuries was 1.95 times $[(95 \% \mathrm{CI}=1.43-2.64), \mathrm{p}<0.001]$. In tables 1 and 2 , descriptive results are shown in short and long terms sickness absence groups.

Table1. Descriptive statistics of individual, lifestyle and occupational characteristic

\begin{tabular}{|c|c|c|c|c|c|c|}
\hline \multirow{2}{*}{ Variable } & \multicolumn{2}{|l|}{ No SA* } & \multicolumn{2}{|c|}{ Short term SA } & \multicolumn{2}{|l|}{ Long term SA } \\
\hline & Mean (SD) & N (\%) & Mean (SD) & N (\%) & Mean (SD) & N (\%) \\
\hline SA day & 0 & & $1.69( \pm 0.73)$ & $\ldots$ & $10.92( \pm 13.7)$ & \\
\hline Sex & $\ldots$ & & & & & \\
\hline Female & & $29(7.6 \%)$ & $\ldots$ & $12(3.5 \%)$ & $\ldots$ & $2(5.1 \%)$ \\
\hline Male & & $351(92.4 \%)$ & & $327(96.5 \%)$ & & $37(94.9 \%)$ \\
\hline Age & & & & $\ldots$ & & \\
\hline $20-30$ & $27.87( \pm 1.93)$ & $113(29.7 \%)$ & $27.68( \pm 1.88)$ & $107(31.6 \%)$ & $28.0( \pm 2.00)$ & $7(40 \%)$ \\
\hline$>30$ & $35.31( \pm 2.89)$ & $267(70.3)$ & $35.24( \pm 2.91)$ & $232(68.4 \%)$ & $35.21( \pm 2.80)$ & $22(60 \%)$ \\
\hline \multicolumn{7}{|l|}{ Marital status } \\
\hline Married & $\ldots$ & $333(87.6 \%)$ & $\ldots$ & $299(88.2 \%)$ & $\ldots$ & $35(89.7 \%)$ \\
\hline Single & & $47(12.4 \%)$ & & $40(11.8 \%)$ & & $4(10.3 \%)$ \\
\hline \multicolumn{7}{|l|}{ Education } \\
\hline University & $\ldots$ & $105(27.6 \%)$ & $\ldots$ & $281(83.1 \%)$ & $\ldots$ & $30(77.5 \%)$ \\
\hline No university & & $275(72.4 \%)$ & & $57(16.9 \%)$ & & $9(22.5 \%)$ \\
\hline \multicolumn{7}{|l|}{ BMI } \\
\hline Normal & $23.09( \pm 1.50)$ & $175(46.1 \%)$ & $23.06( \pm 1.63)$ & $169(49.9 \%)$ & $23.18( \pm 1.50)$ & $22(56.4 \%)$ \\
\hline Overweight & $27.22( \pm 1.32)$ & $168(44.2 \%)$ & $26.81( \pm 1.36)$ & $149(44 \%)$ & $26.95( \pm 1.36)$ & $11(28.2 \%)$ \\
\hline Obesity & $32.33( \pm 2.03)$ & $37(9.7 \%)$ & $32.70( \pm 2.21)$ & $21(6.2 \%)$ & $31.48( \pm 1.18)$ & $6(15.4 \%)$ \\
\hline \multicolumn{7}{|l|}{ Smoking } \\
\hline Never & & $229(78.7 \%)$ & & $266(78.5 \%)$ & & $31(79.5 \%)$ \\
\hline Current & $1.05( \pm 4.62)$ & $81(21.3 \%)$ & $0.66( \pm 2.37)$ & $73(21.5 \%)$ & $0.32( \pm 6.36)$ & $8(20.5 \%)$ \\
\hline \multicolumn{7}{|l|}{ Pack/year } \\
\hline \multicolumn{7}{|l|}{ Job tenure } \\
\hline$<7$ year & $3.73( \pm 2.13)$ & $208(54.7 \%)$ & $4.07( \pm 2.24)$ & $180(53.3 \%)$ & $4.35( \pm 2.10)$ & $23(57.5 \%)$ \\
\hline$\geq 7$ years & $11.77( \pm 3.31)$ & $172(45.3 \%)$ & $11.87( \pm 3.24)$ & $153(46.7 \%)$ & $9.94( \pm 2.90)$ & $17(42.5 \%)$ \\
\hline \multicolumn{7}{|l|}{ Work type } \\
\hline White collar & $\ldots$ & $137(36.1 \%)$ & & $55(16.2 \%)$ & $\ldots$ & $6(15.4 \%)$ \\
\hline Blue collar & & $243(63.9 \%)$ & & $284(83.8 \%)$ & & $33(84.6 \%)$ \\
\hline \multicolumn{7}{|l|}{ Work schedule } \\
\hline Day (fixed) & $\ldots$ & $143(37.6 \%)$ & & $61(18 \%)$ & $\ldots$ & $7(17.9 \%)$ \\
\hline Shift work & & $237(62.4 \%)$ & & $278(82 \%)$ & & $32(84.6 \%)$ \\
\hline
\end{tabular}

*SA: sickness absence 
Table 2. Frequency distribution of physical exposures

\begin{tabular}{|c|c|c|c|}
\hline \multirow[t]{2}{*}{ Variable } & \multirow{2}{*}{$\begin{array}{l}\text { No SA* } \\
\text { N (\%) }\end{array}$} & \multirow{2}{*}{$\begin{array}{l}\text { Short term SA } \\
\text { N (\%) }\end{array}$} & \multirow{2}{*}{$\begin{array}{l}\text { Long term SA } \\
\mathrm{N}(\%)\end{array}$} \\
\hline & & & \\
\hline \multicolumn{4}{|l|}{ Physical hard work } \\
\hline Low & $77(20.3 \%)$ & $41(12.1 \%)$ & $3(7.7 \%)$ \\
\hline High & $303(79.7 \%)$ & $297(87.9 \%)$ & $36(92.3 \%)$ \\
\hline \multicolumn{4}{|l|}{ Sustained sitting work } \\
\hline Low & $254(66.8 \%)$ & $240(71.0 \%)$ & $28(71.8 \%)$ \\
\hline High & $126(33.2 \%)$ & $98(29.0 \%)$ & $11(28.2 \%)$ \\
\hline \multicolumn{4}{|l|}{ Work in front of LCD } \\
\hline Low & $294(77.4 \%)$ & $291(86.1 \%)$ & $34(87.2 \%)$ \\
\hline High & $86(22.6 \%)$ & $47(13.9 \%)$ & $5(12.8 \%)$ \\
\hline \multicolumn{4}{|l|}{ Vibrating surface } \\
\hline Low & $328(86.3 \%)$ & $283(83.7 \%)$ & $30(76.9 \%)$ \\
\hline High & $52(13.7 \%)$ & $55(16.3 \%)$ & $9(23.1 \%)$ \\
\hline \multicolumn{4}{|l|}{ Vibrating tools } \\
\hline Low & $302(79.5 \%)$ & $261(77.2 \%)$ & $33(84.6 \%)$ \\
\hline High & $78(20.5 \%)$ & $77(22.8 \%)$ & $6(15.4 \%)$ \\
\hline \multicolumn{4}{|l|}{ Hand below the knee } \\
\hline Low & $295(77.6 \%)$ & $263(77.8 \%)$ & $25(64.1 \%)$ \\
\hline High & $105(27.6 \%)$ & $75(22.2 \%)$ & $14(35.9 \%)$ \\
\hline \multicolumn{4}{|l|}{ Bending - twisting } \\
\hline Low & $175(46.1 \%)$ & $131(38.8 \%)$ & $12(30.8 \%)$ \\
\hline High & $205(53.9 \%)$ & $207(61.2 \%)$ & $26(66.7 \%)$ \\
\hline \multicolumn{4}{|l|}{ Heavy Lifting } \\
\hline Low & $168(44.2 \%)$ & $121(35.8 \%)$ & $13(40.0 \%)$ \\
\hline High & $212(55.8 \%)$ & $217(64.2 \%)$ & $26(65.0 \%)$ \\
\hline \multicolumn{4}{|l|}{ Hand above shoulder } \\
\hline Low & $275(72.4 \%)$ & $228(67.5 \%)$ & $22(56.4 \%)$ \\
\hline High & $105(27.6 \%)$ & $110(32.5 \%)$ & $17(43.6 \%)$ \\
\hline \multicolumn{4}{|l|}{ Repetitive movement } \\
\hline Low & $120(31.6 \%)$ & $97(28.7 \%)$ & $12(30.8 \%)$ \\
\hline High & $260(68.4 \%)$ & $241(71.3 \%)$ & $27(69.2 \%)$ \\
\hline \multicolumn{4}{|l|}{ Sensitive work } \\
\hline Low & $225(59.2 \%)$ & $180(53.3 \%)$ & $20(51.3 \%)$ \\
\hline High & $155(40.8 \%)$ & $158(46.7 \%)$ & $19(48.7 \%)$ \\
\hline \multicolumn{4}{|l|}{ Total physical score } \\
\hline Low & $212(55.8 \%)$ & $161(47.6 \%)$ & $17(43.6 \%)$ \\
\hline High & $168(44.2 \%)$ & $177(52.4 \%)$ & $22(56.4 \%)$ \\
\hline
\end{tabular}

*SA: sickness absence 
Chi-square analysis and multivariate analysis (Binary Logistic Regression) results are shown in tables III. According to this table: male workers had more sickness absence than female workers and this gender differences was more evident in the short-term absence [OR=2.25(95\% CI $=1.13-4.48), p=0.018]$. Workers with non-university education had 1.8 times more short-term absences. In our study, the highest OR in incidence of sickness absence was associated with two occupational factors: blue collar [OR=3.38 (95\% CI=1.39-8.24), $\mathrm{p}=0.005]$ and shift works $[\mathrm{OR}=2.78(95 \% \mathrm{CI}=1.2-6.48), \mathrm{p}=0.013]$. These variables were the most important risk factors in incidence of short and long term sickness absences. Among the physical exposure variables, risk factors associated with the higher incidence of sickness absence were physical hard work [OR $=3.05$ ( $95 \% \mathrm{CI}=1.01-10.1), \mathrm{p}=0.049]$, working in front of computer screen [OR=1.82(95\% CI $=1.23-2.69), \mathrm{p}=0.002]$, over shoulder working [OR=1.99(95\% $\mathrm{CI}=1.02-3.81), \mathrm{p}=0.04]$, frequent bending -twisting [OR=1.86 $(95 \% \mathrm{CI}=1.091-4.02), \mathrm{p}=0.008]$, and heavy lifting [OR=1.64 (95\% $\mathrm{CI}=1.19-2.25), \mathrm{p}=0.002]$.

In regression analysis in the final multivariate model, blue collar [OR=2.03 $(95 \% \mathrm{CI}=1.30-3.14), \mathrm{p}=0.002]$, shift work [OR=1.74 (95\% $\mathrm{CI}=1.13-2.65), \mathrm{p}=0.009]$, Bending-twisting [OR=1.85 (95\% $\mathrm{CI}=1.56-3.29), \mathrm{p}=0.009]$, and heavy lifting $[\mathrm{OR}=1.09(95 \% \mathrm{CI}=1.09-1.63), \mathrm{p}=0.027]$ remained significant after adjusted for Confounding factors.

Table 3. Chi-square and logistic regression results for risk factors of sickness absence.

\begin{tabular}{|c|c|c|c|c|c|c|}
\hline \multirow[b]{2}{*}{ Variable } & \multicolumn{2}{|l|}{ Short term SA* } & \multicolumn{4}{|l|}{ Long term SA } \\
\hline & OR(95\% CI) & $\mathbf{P}$ & OR(95\% CI) & $\mathbf{P}$ & $\mathbf{L R}^{* *}$ & $\mathbf{P}$ \\
\hline \multicolumn{7}{|l|}{ Sex } \\
\hline Female (ref) & 1 & & 1 & & 1 & \\
\hline Male & $2.25(1.13-4.48)$ & 0.018 & $1.52(0.35-6.66)$ & 0.75 & $1.07(0.50-2.25)$ & 0.85 \\
\hline \multicolumn{7}{|l|}{ Age } \\
\hline $20-30$ & 1 & & 1 & & & \\
\hline$>30$ & $2.77(1.002-7.77)$ & 0.59 & $1.92(0.96-4.90)$ & 0.68 & & \\
\hline \multicolumn{7}{|l|}{ Marital status } \\
\hline Married(ref) & 1 & & 1 & & & \\
\hline Single & $1.81(0.61-5.35)$ & 0.27 & $1.35(0.46-3.96)$ & 0.58 & & \\
\hline \multicolumn{7}{|l|}{ Education level } \\
\hline University (ref) & 1 & & 1 & & 1 & \\
\hline No university & $1.89(1.31-2.72)$ & $<0.001$ & $1.21(0.33-1.28)$ & 0.60 & $1.09(0.64-1.53)$ & 0.77 \\
\hline \multicolumn{7}{|l|}{ BMI } \\
\hline$<25$ (ref) & 1 & & 1 & & & \\
\hline$\geq 25$ & $0.86(0.64-1.16)$ & 0.34 & $0.66(0.57-2.56)$ & 0.21 & & \\
\hline \multicolumn{7}{|l|}{ Smoking } \\
\hline Never (ref) & 1 & & 1 & & & \\
\hline Current & $1.04(0.73-1.49)$ & 0.80 & $1.34(0.57-3.14)$ & 0.49 & & \\
\hline \multicolumn{7}{|l|}{ Work type } \\
\hline White collar(ref) & 1 & & 1 & & 1 & \\
\hline Blue collar & $2.98(2.08-4.27)$ & $<0.001$ & $3.38(1.39-8.24)$ & 0.005 & $2.03(1.30-3.14)$ & $0.002 *$ \\
\hline \multicolumn{7}{|l|}{ Work schedule } \\
\hline Day work(ref) & 1 & & 1 & & 1 & \\
\hline Shift work & $2.76(1.96-3.93)$ & $<0.001$ & $2.78(1.2-6.48)$ & 0.013 & $1.74(1.13-2.65)$ & $0.009^{*}$ \\
\hline \multicolumn{7}{|c|}{ Physical hard work } \\
\hline Low(ref) & 1 & & 1 & & 1 & \\
\hline
\end{tabular}


High $\quad 1.84(1.22-2.78) \quad 0.003 \quad 3.05(1.01-10.1) \quad 0.05 \quad 1.23(0.78-1.94) \quad 0.35$

Sitting work

Low (ref)

High

$1.22(0.89-1.68)$

$1.24(0.61-2.50) \quad 0.54$

Work in front of LCD

Low (ref)

High

\section{1}

$1.82(1.23-2.69)$
1

0.002

$1.74(0.71-4.28)$

0.21

$1.39(0.8-2.42)$

Vibrating surface

Low (ref)

High

1

$1.19(0.79-1.79)$

0.39

1

$1.81(0.81-4.02) \quad 0.14$

Vibrating tools

Low(ref)

1

High

$1.13(0.79-1.62)$

0.47

1

$1.30(0.55-3.04) \quad 0.53$

Hand below the knee

Low(ref)

High

\section{1}

$1.00(0.70-1.42)$

0.98

\section{1}

$1.94(0.96-3.90) \quad 0.58$

Bending- twisting

Low(ref)

1

High

1.37 (1.01-1.84)

1

0.038

$1.86(1.09-4.02)$

1

Heavy Lifting

Low(ref)

High

1

$1.64(1.19-2.25)$

1
$0.002 \quad 1.47(0.74-2.90) \quad 0.26$

1

$1.06(1.09-1.63) \quad 0.027 *$

Over shoulder

Low(ref)

1

High

$1.25(0.91-1.73)$

0.15

1

$1.99(1.02-3.81) \quad 0.04$

Repetitive movement

Low(ref)

1

High

$1.16(0.84-1.60)$

0.34

1

$1.05(0.51-2.14) \quad 0.89$

Sensitive work

Low(ref)

High

1

$1.22(0.96-1.64)$

0.17

1

$1.32(0.68-2.55) \quad 0.40$

Total physical score

Low(ref)

High

1

1

$1.35(1.08-1.81)$

0.044

$1.58(0.84-3.07)$

$1.06(0.77-1.46)$

0.71

*SA: sickness absence ** LR: logistic regression

\section{Discussion}

In this study, we assessed the pattern of sickness absence in automotive industry workers and evaluated the impact of individual factors, occupational and physical exposures on this outcome. Our study showed that Short term sickness absences were associated with minor diseases while the long-term sickness absences were due to serious disorders which caused inability to work.

The most common causes of absence from work in order of frequency were respiratory illnesses (such as common colds and Influenza), musculoskeletal diseases, digestive diseases (e.g. gastroenteritis) and injuries. 
Musculoskeletal disorders increased the danger of long term sickness absence by $4 / 33$ times and injuries by 1.95 times. These results are consistent with the results of some previous studies. In one study, the main reason for the sickness absence were respiratory diseases, musculoskeletal disorders, gastrointestinal diseases and injuries (Rahme et al., 2006) and in another study conducted by, the most common causes of sickness absence were colds and influenza and the highest proportion of days lost was related to musculoskeletal disorders (Kremer et al., 2010). (Lund et al., 2009) and as well as (Roberto Ferreira et al., 2012) obtained similar results. Colds and flu are prevalent respiratory diseases. The viral nature of this disease increases the risk of contagion to others. Employees usually work in closed spaces with poor ventilation that leads to an increased episode of disease transmission. Auto industry imposes high physical exposure and poor ergonomic state on workers. Long-term exposure to these conditions can superpose workers at risk for musculoskeletal problems. Injuries results in most working-day lost. Fractures (a common group of injury in our study) require a long time to heal, and during this time, worker can't work and it results in long term absence from work.Our findings showed that gender, education level and aging were significantly effective on occurrence of absence from work. These findings are compatible with the results of previous studies. For instance, one research found that the risk of sickness absence in male workers was higher than females (Kivimaki et al., 2002). Similar results in a study conducted in Sweden confirmed this gender differences (Lund T et al., 2009). In a cross-sectional study demonstrated that sickness absence declines with increasing level of education (Aaviksoo et al., 2013). In a study, association between increased sickness absence and aging was found (Alavinia et al., 2009).

Among the occupational factors, blue collar and shift works were the most important risk factors for incidence of absenteeism. White collar employees were not in contact with harmful hazards in the manufacturing sector and therefore had lower sickness absence. Shift working disturbances of the circadian rhythm system and thus reduced wellbeing, increase morbidity and the risk of many diseases (Rom, 2007). Some previous studies showed that blue collar workers had more sickness absence than white collar workers (Aaviksoo et al., 2013; Alavinia et al., 2009). The results of our study show that physical exposures like heavy lifting, bending-twisting of lumbar and hard physical work are associated with occurrence of sickness absence. This correlation may be due to increase incidence of musculoskeletal disorders. In previous studies the relationship between physical factors and sickness absence was seen: exposure to ergonomic factors such as heavy lifting repetitive movements can leads to increased sickness absence (d'Errico et al., 2012). Severe back bending, over shoulder working and heavy lifting were main factors causing sickness absence (Lond et al., 2009). In one study, physical exposures, lifting and intense physical conditions affect short term and long term sickness absences (Alavinia et al., 2009). There was significant relationship between physical exposures and sickness absence (Labriola et al., 2006; Aaviksoo et al., 2013).

In our study, data related to sickness absence was obtained from a computerized record system; thus were reliable and had no recall bias. But because of the cross-sectional nature of the study, identifying the causal relationship between risk factors and sickness absence was not possible. The healthy worker effect may alter the pattern of diseases due to the early departure of workers suffering from debilitating illnesses.

Finally, in this study we found that physical exposures (frequent bending-twisting and heavy lifting) accompanied by other occupational exposures (shift working and work as a blue collar worker) and also some individual factors are the most prominent factors affecting the incidence of sickness absence. Thus special attention should be paid to control these risk factors. Weight loss motivating policies, encouraging smoking cessation, educating workers, improving ergonomic principals and working conditions would be beneficial.

\section{Acknowledgements}

This study was conducted with support from the Deputy for Research at Iran University of Medical Sciences Also we deeply thank the manufacturing industrial company workers whom participated in our study.

\section{References}

Absence Management. Sickness Absence Costs. (2011). Retrieved from http://www.salus.co.uk/absence-management/sickness-bsence-costs/Pages/default.aspx. (Cited:31-08-2014).

Aaviksoo, E., Baburin, A., \& Kiivet, R. A. (2013). Risk factors for sickness absence among Estonian Employees. Occupational Medicine, 63, 156-159. http://dx.doi.org/10.1093/occmed/kqs222.

Alavinia, S. M., van den Berg, T. I. J., van Duivenbooden, C., Elders, L. A. M., \& Burdorf, A. (2009). Impact of work-related factors, lifestyle, and work ability on sickness absence among Dutch construction workers. Scand J Work Environ Healt, 35, 325-333. http://dx.doi.org/10.5271/sjweh.1340

Alipour, A., Ghaffari, M., \& Jensen, I. (2007). Reliability and validity study of Persian modified version of 
MUSIC (musculoskeletal intervention center) -Norrtalje questionnaire. BMC Musculoskeletal Disorders, 8, 88. http://dx.doi.org/10.1186/1471-2474-8-88

Bruce Japsen, U. S. (2014). Workforce Illness Costs \$576B Annually From Sick Days To Workers Compensation. 9/12/2012. Retrieved August 31th, 2014, from http://www.forbes.com/sites/brucejapsen/2012/09/12/us-workforce-illness-costs-576b-annually-from-sick-days-to-workers compensation/ (cited:).

Bultmann, U., Huibers, M. J. H., van Amelsfoort, L. P. G. M., Kant, I. J., Kasl, S. V., \& Swaen, G. M. H. (2005). Psychological distress, fatigue and long-term sickness absence: prospective results from the Maastricht Cohort Study. J Occup Environ Med 47:941-947. http://dx.doi.org/10.1097/01.jom.0000172865.07397.

d'Errico, A., \& Costa, G. (2012). Socio-demographic and work-related risk factors for medium- and long-term sickness absence among Italian workers. The European Journal of Public Health Advance, 22, 683-688. http://dx.doi.org/10.1093/eurpub/ckr140

Dekkers-Sanchez, P. M., Hoving, J. L., Sluiter, J. K., \& Frings-Dresen, M. H. W. (2008). Factors associated with long- term sick leave in sick listed employees: A systematic review. Occup Environ Med, 65, 153-157. http://dx.doi.org/10.1136/oem.2007.034983.

Duijts, S. F., Kant, I., Swaen, G. M., van den Brandt, P. A., \& Zeegers, M. P. (2007). A meta-analysis of observational studies identifies predictors of sickness absence. J Clin Epidemio, l60, 1105-1115. http://dx.doi.org/10.1016/j.jclinepi.2007.04.008

Ferreira, R. C., Griep, R. H., Fonseca Mde, J., \& Rotenberg, L. (2012).A multifactorial approach to sickness Absenteeism among nursing staff. Rev. Saúde Pública 46:259-68. http://dx.doi.org/10.1590/S003489102012005000018

Ferrie JE, Vahtera J, Kivimaki M et al. (2009). Diagnosis-specific sickness absence and all-cause mortality in the GAZEL study. J Epidemiol Community Health, 63, 50-55. http://dx.doi.org/10.1136/jech.2008.074369

Head, J., Ferrie, J. E., Alexanderson, K., Westerlund, H., Vahtera, J., \& Kivimaki, M. (2008). Diagnosis-specific sickness absence as a predictor of mortality: the Whitehall II prospective cohort study. BMJ 337:a1469. http://dx.doi.org/10.1136/bmj.a1469

Kivimaki, M., Ferrie, J. E., Hakberg, J. et al. (2007). Diagnosis-specific sick-leave as a risk marker for disability pension in a Swedish population. $J$ Epidemiol Community Health, 61, 915-920. http://dx.doi.org/10.1136/jech.2010.126789

Kivimaki, M., Vahtera, J., Elovainio, M., Lillrank, B., \& Kevin, M. V. (2002). Death or illness of a family member, violence, interpersonal conflict, and financial difficulties as predictors of sickness absence: longitudinal cohort study on psychological and behaviorial links. Psychosom Med., 64, 817-825. http://dx.doi.org/10.1097/01.PS Y.00000 31576.42041.B1

Kremer A. M, \& Steen beek R. (2010). Avoidable Sickness Absence in a Dutch Working Population. JOccup Rehabil, 20, 81-89. http://dx.doi.org/10.1007/s10926-009-9200-5.

Kristensen, T. R., Jensen, S. M., Kreiner, S., \& Mikkelsen, S. (2010). Socioeconomic status and duration and pattern of sickness absence: a 1-year follow-up study of 2331 hospital employees. BMC PublicHealth 10:643. http://dx.doi.org/10.1186/1471-2458-10-643 12

Labriola M, Lund T, \& Burr H. (2006). Prospective study of physical and psychosocial risk factors for sickness absence. Occup Med, 56, 469-474. http://dx.doi.org/10.1093/occmed/kq1058

Lund, T., Christensen, K. B., Vaez, M., Labriola, M., Josephson, M., Villadsen, E. et al. (2009). Differences in sickness absence in Sweden and Denmark: the cross national HAKNAK study. European Journal of Public Health, 19, 343-349. http://dx.doi.org/10.1093/eurpub/ckn128

Lund, T., \& Labriola, M. L. (2009). Sickness absence in Denmark: research, results, and reflections. Scand J Work Environ Health Suppl., 7, 5-14.

Niedhammer, I., Chastang, J. F., David, S., \& Kelleher, C. (2008). The contribution of occupational factors to social inequalities in health: fi ndings from the national French SUMER survey. Soc Sci Med., 67, 1870-1881. http://dx.doi.org/10.1016/j.socscimed

Ose, S. O. (2005). Working conditions, compensation and absenteeism. J Health Econ., 24, 161-88. http://dx.doi.org/10.1016/j.jhealeco.2004.07.001

Rahme, D. R., Razzouk, G. N., Musharrafieh, U. M., Rahi, A. C., \& Akel, M. M. (2006). Sickness-Related 
Absence Among Employees at Tertiary Care Center in Lebanon. Environmental \& Occupational Health, 61, 279-284. http://dx.doi.org/10.3200/AEOH.61.6.279-284

Rom, W. (2007). Environmental and Occupational Medicine. Lippincott Williams \& Wilkins, (4th ed., pp. 1359-1363).

Vingrd, E., Lindberg, P., Josephson, M., Voss, M., Heijbel, B., ... Alfredsson, L. (2005). Long-term sick-listing among women in the public sector and its associations with age, social situation, lifestyle, and work factors:
a three-year
follow-up
study.
Scand
J Public
Health,
335 ,
370-375.
http://dx.doi.org/10.1080/14034940510005860

Virtanen, P., Siukola, A., Luukkaala, T., Savinainen, M., Arola, H., Nygård, C.-H., et al. (2008). Sick leaves in four factories - do characteristics of employees and work conditions explain differences in sickness absence between workplaces? Scand J Work Environ Health, 34, 260-266. http://dx.doi.org/10.5271/sjweh.1225

Voss, M., Floderus, B., \& Diderichsen, F. (2004). How do job characteristics, family situation, domestic work, and lifestyle factors relate to sickness absence? A study based on Sweden post. J Occup Environ Med, 46, 1134-1143. http://dx.doi.org/10.1097/01.jom.0000145433.65697

WHO. (2010). International Classification of Diseases (ICD) version 10. Retrieved August 31th, 2014, from http://apps.who.int/classifications/icd10/browse/2010/en

Zenz, C. (1994). Occupational Medicine. (4th ed., pp. 987-996), New York, Sanders.

\section{Copyrights}

Copyright for this article is retained by the author(s), with first publication rights granted to the journal.

This is an open-access article distributed under the terms and conditions of the Creative Commons Attribution license (http://creativecommons.org/licenses/by/3.0/). 